\title{
In-line filtration of intravenous infusion may reduce organ dysfunction of adult critical patients
}

\author{
Elke Schmitt ${ }^{1,2}$, Patrick Meybohm ${ }^{1,3^{*}}$, Eva Herrmann ${ }^{2}$, Karin Ammersbach ${ }^{4}$, Raphaela Endres ${ }^{1}$, Simone Lindau ${ }^{1}$, \\ Philipp Helmer ${ }^{1}$, Kai Zacharowski ${ }^{1 *}$ and Holger $\mathrm{Neb}^{1}$
}

\begin{abstract}
Background: The potential harmful effects of particle-contaminated infusions for critically ill adult patients are yet unclear. So far, only significant improved outcome in critically ill children and new-borns was demonstrated when using in-line filters, but for adult patients, evidence is still missing.

Methods: This single-centre, retrospective controlled cohort study assessed the effect of in-line filtration of intravenous fluids with finer 0.2 or $1.2 \mu \mathrm{m}$ vs $5.0 \mu \mathrm{m}$ filters in critically ill adult patients. From a total of $n=3215$ adult patients, $n=3012$ patients were selected by propensity score matching (adjusting for sex, age, and surgery group) and assigned to either a fine filter cohort (with 0.2/1.2 $\mu \mathrm{m}$ filters, $n=1506$, time period from February 2013 to January 2014) or a control filter cohort (with $5.0 \mu \mathrm{m}$ filters, $n=1506$, time period from April 2014 to March 2015). The cohorts were compared regarding the occurrence of severe vasoplegia, organ dysfunctions (lung, kidney, and brain), inflammation, in-hospital complications (myocardial infarction, ischemic stroke, pneumonia, and sepsis), inhospital mortality, and length of ICU and hospital stay.
\end{abstract}

Results: Comparing fine filter vs control filter cohort, respiratory dysfunction (Horowitz index 206 (119-290) vs 191 $(104.75-280) ; P=0.04)$, pneumonia (11.4\% vs $14.4 \% ; P=0.02)$, sepsis (9.6\% vs $12.2 \% ; P=0.03)$, interleukin-6 (471.5 (258.8-1062.8) $\mathrm{ng} / \mathrm{l}$ vs $540.5(284.5-1147.5) \mathrm{ng} / \mathrm{l} ; P=0.01)$, and length of ICU (1.2 (0.6-4.9) vs 1.7 (0.8-6.9) days; $P<0.01)$ and hospital stay (14.0 (9.2-22.2) vs $14.8(10.0-26.8)$ days; $P=0.01)$ were reduced. Rate of severe vasoplegia ( $21.0 \%$ vs $19.6 \% ; P>0.20)$ and acute kidney injury (11.8\% vs $13.7 \% ; P=0.11$ ) was not significantly different between the cohorts.

Conclusions: In-line filtration with finer 0.2 and $1.2 \mu \mathrm{m}$ filters may be associated with less organ dysfunction and less inflammation in critically ill adult patients.

Trial registration: The study was registered at ClinicalTrials.gov (number: NCT02281604).

Keywords: Intensive care, Infusion management, In-line filtration, Particles, Organ dysfunction, Inflammation

\section{Background}

The intravenous administration of both fluids and drugs represents one of the main therapy pillars within intensive care medicine. Contamination with particles, however, and their potential harmful effects, especially for critically ill patients is a suspected issue [1-4]. Recent studies [5-7] showed that the particle load is significantly higher without

\footnotetext{
*Correspondence: patrick.meybohm@kgu.de; kai.zacharowski@kgu.de ${ }^{1}$ Department of Anaesthesiology, Intensive Care Medicine and Pain Therapy, University Hospital Frankfurt, Frankfurt am Main, Germany

Full list of author information is available at the end of the article
}

in-line filters and that in-line filtration may be an effective tool in preventing particle contamination to patients. Today, at least three different commercial in-line filter systems are available. The $5.0-\mu \mathrm{m}$ in-line filter reduces rough particles (glass, rubber, plastic). The potential advantage of the finer positively charged 0.2 and $1.2 \mu \mathrm{m}$ in-line filters is that they can hold back not only glass, rubber, and plastic particles but also particles from drug incompatibilities, air, microorganisms (bacteria size 1-3 $\mu \mathrm{m}$ ), and smaller endotoxins [8]. Therefore, catheter-related bloodstream

(C) The Author(s). 2019 Open Access This article is distributed under the terms of the Creative Commons Attribution 4.0 International License (http://creativecommons.org/licenses/by/4.0/), which permits unrestricted use, distribution, and 
infections are a potential target of prevention via in-line filtration, too.

In general, potential systemic effects of microparticles on different organs may depend on material, size, amount, and patient population. Recent studies focussed on critically ill children and new-borns showing a significant reduction of complications, e.g. thrombosis, sepsis, and organ failure as well as a reduction of length of stay in ICU [9-12], while others [13, 14] found no benefits. Furthermore, post-mortem studies on patients with acute respiratory distress syndrome (ARDS) suggest a harmful effect of those particles especially for the lungs and have shown that infusion therapy can lead to a particle-induced mechanic vascular occlusion and to intravascular formation of foreign bodies [15-18]. In vitro studies demonstrated a particle-induced modulation of the immune system [19]. The German Society of Anaesthesiology and Intensive Care Medicine and the Berufsverband Deutscher Anästhesisten both strongly suggest the use of particle filters with size always adapted to the type of fluid or drug (chosen as small as possible due to the suspected harmful effects of very small particles in the range of $2-100 \mu \mathrm{m}$ ) [20]. Organisations such as the PDA (Parenteral Drug Association) Europe offer regular training for physicians to transfer actual knowledge about potential harmful effects of particles for patients and also participate actively in research activities on particles in parenteral drugs. But the evidence on the benefits for adult intensive care patients is still unclear.

The aim of this study was to elucidate if the use of the finer 0.2 or $1.2 \mu \mathrm{m}$ in-line filters was superior in comparison to the larger $5 \mu \mathrm{m}$ in-line filter within the framework of i.v. fluid and drug management for adult critical ill patients.

\section{Materials and methods Study design}

This single-centre, retrospective controlled cohort study covering the period between February 2013 and April 2015 assessed the effects of in-line filtration of intravenous fluids on the reduction of complications in critically ill adult patients of a tertiary German hospital.

Approval of the study protocol was obtained from the local ethics committee (Goethe-University Frankfurt am Main, ref. 8/14 from 30 January 2014). The study was registered at ClinicalTrials.gov (NCT02281604). Funding was exclusively provided by internal departmental funding.

\section{Patient enrolment and cohorts}

All adult (age $\geq 18$ years) critical patients who were admitted to the University Hospital Frankfurt between February 2013 and March 2015 and had at least 1 admission to the 34-bed intensive care unit (ICU) were included. Admission to the ICU for more than one time during the same hospital stay was not an a priori exclusion criteria, and the information of these ICU stays was cumulated. Patients admitted to the hospital more than one time during this period (ranging from returns after weeks to months or years) were not excluded from the study, but only the first hospital stay was used.

Until February 2013, no in-line filters were used routinely on the ICU, intraoperatively or on the regular wards. To reduce the risk of particle contamination, larger $5 \mu \mathrm{m}$ in-line filters have been routinely introduced intraoperatively and on all normal care stations from February 2013 on up to the present. On the ICU instead, in the period from February 2013 to January 2014, finer 0.2 or $1.2 \mu \mathrm{m}$ in-line filters were routinely used $(0.2 \mu \mathrm{m}$ Sterifix for aqueous solutions and $1.2 \mu \mathrm{m}$ Intrapur for lipid-containing mixtures) (Fig. 1). In February 2014, filter systems on the ICU were again switched to the larger $5 \mu \mathrm{m}$ in-line filters during a cost-reduction initiative (about $15 €$ per 0.2 or $1.2 \mu \mathrm{m}$ in-line filter and doubts regarding the efficacy of the finer filters), and the remaining 0.2 or $1.2 \mu \mathrm{m}$ in-line filters were consumed in parallel. Thus, since April 2014, only larger $5 \mu \mathrm{m}$ in-line filters have been used on the ICU. The peripheral lines were protected equally as the central lines by the respective in-line-filters of each time period and ward. Usually, the filters were placed directly behind the threeway cock of the (central) venous line (Fig. 2).

While patients admitted to the ICU between February 2013 and January 2014 were assigned to the fine filter cohort (finer 0.2 or $1.2 \mu \mathrm{m}$ in-line filters; $n=1621$ ), patients admitted between April 2014 and March 2015 were assigned to the control filter cohort (larger $5 \mu \mathrm{m}$ in-line filters; $n=1594$ ).

To account for differences in patient characteristics (exact matching for surgery group and sex, nearest neighbour matching with respect to age), a propensity score matching was performed, which resulted in the final number of $n=1506$ subjects for both cohorts.

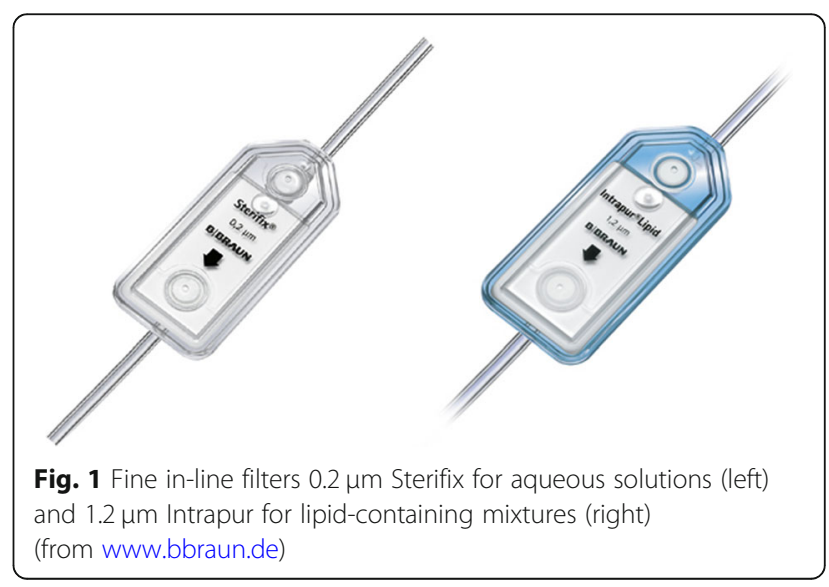




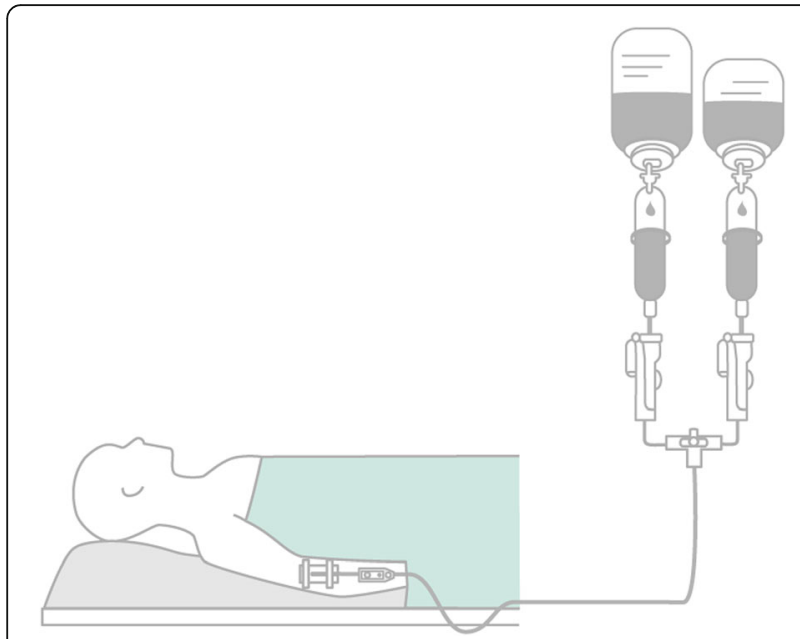

Fig. 2 Scheme of in-line filter inserted into the IV lines (from www.bbraunforsafety.com)

No dropout occurred as routine data could be followed up until hospital discharge and no patient consent was needed.

\section{Endpoints}

Microparticles are suspected to be responsible for inflammation of any kind that could lead to different organ manifestations. Inflammation on its own can cause vasodilatation via increased NO production, possibly leading to severe vasoplegia, also known as vasodilatory shock. As this complex syndrome can in fact only be assessed clinically by the vasopressor dosage necessary to maintain an acceptable mean arterial blood pressure, we tried to identify patients suffering from this syndrome by choosing high dose norepinephrine as one of the most appropriate potential surrogate parameters [21].

Primary endpoint of this epidemiological study was the rate of severe vasoplegia [22-24] defined by a continuous norepinephrine rate $\geq 0.3 \mu \mathrm{g} / \mathrm{kg} / \mathrm{min}$ for at least $1 \mathrm{~min}$. Patients that did not receive any administration of norepinephrine reported in the data files were counted as patients with dose zero due to the fact that only records exist if patients did receive norepinephrine. Values of norepinephrine rates $>1.0 \mu \mathrm{g} / \mathrm{kg} / \mathrm{min}$ were discarded as unrealistic on our ICU. In addition, we analysed the rate of patients receiving norepinephrine and also methylene blue (which is an additional option to treat vasoplegia) to obtain a more comprehensive overview on this endpoint.

The following secondary endpoints were recorded until hospital discharge:

(i) Multiple-organ dysfunction (assessed by maximal SOFA score, additionally SAPS II and TISS-10/ TISS-28). (ii) Incidence and severity of lung dysfunction (defined by minimal Horowitz index (obtained by the ratio of the values of $\mathrm{paO}_{2}$ and $\mathrm{FIO}_{2}$ ) and ARDS score [25] (obtained by calculating the scores with the standard definition from the minimal Horowitz index of each patient $(0-100=$ severe ARDS (score 3), 101-200 = moderate ARDS (score 2), 201-300 = mild ARDS (score 1), 301-... = no ARDS (score $0)$ )). Information on duration of mechanical ventilation or airway pressures was not present.

(iii) Incidence and severity of acute kidney injury (AKI) was defined by a modified AKIN [26] score based only on creatinine values before the first dialysis without information on urine output $(0=$ no AKI, $1=$ mild AKI, 2 = moderate AKI, 3 = severe AKI) and by the dialysis rate as albuminuria and glomerular filtration rate were not available in this retrospective study to analyse the current recommended score from KDIGO (Kidney Disease Improving Global Outcome) (https://kdigo.org/).

(iv) Incidence of delirium (maximal delirium score defined by ICDSC standard screening).

(v) Grade of inflammation (by maximal interleukin-6 (IL-6) values [27, 28]). Interleukin-6 levels were dosed routinely every 6 or at least $12 \mathrm{~h}$ (at 4 am and $4 \mathrm{pm}$ ) in our intensive care unit and, according to specific individual needs for a critical patient, additionally also occasionally at individual extra time points in between, whereas other inflammation markers, e.g. C-reactive protein or procalcitonin, were not determined routinely. Blood samples were sent to the central lab where an electrochemiluminescence immunoassay (ECLIA) test was performed. The measurement usually takes 30-60 min in case of an emergency blood sample. As any unspecific activation of macrophages generally leads to an elevation of IL-6 levels in patients' serum at first, this marker is sensitive in detecting ongoing inflammation [29].

(vi) Length of stay on ICU (cumulated time in days defined by admission/discharge dates and times) and in hospital (time in days defined by admission/ discharge date and time).

(vii) In-hospital mortality over 28 days and over total hospital stay (defined by discharge code).

(viii)Rate of in-hospital complications and morbidities (acute myocardial infarction, acute ischemic stroke, pneumonia, sepsis, defined by their ICD-10 codes from diagnoses).

(ix) Incidence and severity of lung/cardiac dysfunction (assessed by rate of ECMO and cumulated ECMO time, defined by start/end dates and times). 
Patients who need higher norepinephrine rates might also suffer from sepsis or septic shock, but especially, inflammation after cardiopulmonary bypass triggers vasoplegia as well. In contrast, the diagnosis sepsis is reasonably different from inflammation and vasoplegia; therefore, we analysed these two endpoints independently.

\section{Data collection and statistical analysis}

Routine data were obtained from the hospital information systems ORBIS (AGFA HealthCare, Bonn, Germany) [30] and the electronic patient data management system Metavision (iMDsoft, Tel Aviv, Israel) [31], which was first established in 2013 on the ICU. No additional study documentation on CRFs/eCRFs was performed. The documentation of the patient-related medical data was performed by using a pseudonymised patient ID or case number. No characteristics that would allow the direct identification of certain patients during the data analysis were transmitted. The study data were protected from foreign access, and only members of the study team had access to it.

The exported data were screened for apparent inconsistencies (e.g. inverted start/end dates, values being clearly out of the normal reference range by many orders) and missing information (e.g. type of discharge, measurements, medication) to detect documentation errors. Missing information was corrected manually, where possible, based on the original full patient file from the source hospital information systems AGFA ORBIS or Metavision. Patients with missing laboratory or score values for an endpoint were only excluded from that endpoint but not from the study. For patients not mentioned in the therapeutic intervention data (e.g. norepinephrine, dialysis), it was assumed that those patients had no intervention (e.g. zero doses, no dialysis). For patients with cardiac surgery, the potential event of myocardial infarction was not taken into account, as well as for patients with neurosurgery not the potential event of ischemic stroke (such patients were treated as having no event) to exclude potential pre-existing diseases.

The information about different ICU stays during the same hospital stay was then summarised, and patients were assigned to either the fine filter cohort (if all ICU stays were during the fine filter period), the control cohort (if all ICU stays were during the control filter period), or excluded (if neither of the two).

Statistical analysis was performed with the use of the statistic software R ( R Foundation for Statistical Computing, Vienna, Austria) version 3.4.1 [32] with the package "MatchIt" version 3.0.2 for propensity score matching. Additional analysis was performed with BiAS (epsilon-Verlag, Frankfurt/Main, Germany, maintained by Institute of Biostatistics, Goethe University Frankfurt, Germany) for Windows version 11.06 [33]. Although if due to the large number of patients per cohort that depended only on the time period, the patient characteristics were most likely already approximately equally distributed in each cohort, we aimed to minimise potential bias and effects in the outcomes as best as possible. Therefore, in the total cohort of $n=$ 3215 patients, a propensity score matching adjusting pairwise for the main characteristics-surgery group, sex, and age in each cohort-was introduced that lead to a total of $n=3012$ patients ( $n=1506$ each per fine filter and control filter cohort). The propensity score matching was performed completely independent from the later outcome variables (such as Horowitz, creatinine, IL-6), and especially, no patient selection was done. For other minor characteristics (such as scores or baseline values), no matching was performed, as this would need an even much higher amount of patients to match for more characteristics equally in both cohorts. Further pre-tests (Shapiro-Wilk) were performed to determine if any of the endpoints or their logarithmised values followed a normal distribution. As deviations from normal distribution could be confirmed in all tests for the continuous endpoints, the Mann-Whitney $U$ tests were performed for group comparisons.

There was no need to perform any significance correction for multiple testing, as our scope was to analyse the outcomes for different secondary endpoints independently from each other and from the main endpoint.

The main hypothesis was to test if the use of the finer 0.2 or $1.2 \mu \mathrm{m}$ in-line filters was superior in comparison to the larger $5 \mu \mathrm{m}$ in-line filter with respect to the incidence rate of severe vasoplegia.

For sample size estimation, a risk reduction of $20 \%$ by the usage of the finer 0.2 or $1.2 \mu \mathrm{m}$ in-line filters from an incidence rate of 10 to $8 \%$ for the primary endpoint was considered as clinically relevant. This difference could be detected with a chi-square test with at least $80 \%$ power and a significance level of $\alpha \leq$ 0.05 , if about $n=1400$ subjects were enrolled in each cohort, as calculated by $G$ *Power (Heinrich Heine University of Duesseldorf, Germany) [34] in the original study analysis plan. The evaluation of the therapy effect was performed by a logistic regression (with regressor variables age, sex, surgery group, and cohort), and the test decision (for difference between the cohorts) was carried out with the Wald test for the coefficients of the therapy effect with R (package "survey" version 3.33). The risk reduction was quantified as odds ratio (OR) with 95\% confidence interval.

The secondary hypotheses were to test if the use of the finer 0.2 or $1.2 \mu \mathrm{m}$ in-line filters was superior to the use of the larger $5 \mu \mathrm{m}$ in-line filter regarding the incidence of the secondary endpoints. Risk reduction was quantified as risk ratio (RR) with $95 \%$ confidence interval. Both cohorts were compared regarding the 
differences of incidence rates and their 95\% confidence interval (CI), of mean \pm standard error (SE) for continuous or median values with quartiles for at least ordinal endpoints. Differing from that, median values were also used for continuous endpoints if their distribution was not approximately symmetric.

In addition, appropriate tests (exact Fisher or chisquare for rates and Mann-Whitney $U$ for all other endpoints) for significance were performed. Effect size was reported as risk ratio (range from 0 to infinity) for binary endpoints and by the Mann-Whitney $U(\mathrm{MW})$ estimator (range from 0 to 1 ) for at least ordinal endpoints, each with corresponding 95\% CI. Where appropriate, additionally, also linear or logistic regression models dependent on cohort, age, sex, surgery group, and baseline values were used to perform a Wald test for significance of the cohort and the related odds ratio was reported where appropriate. The latter models provide the advantage of considering potential influence factors (e.g. baseline values) but are less robust than non-parametric tests, on which we primarily based our results.

\section{Results}

Forty-one percent of the matched patients underwent only cardiac surgery (and additionally about $22 \%$ of the total surgeries in the mixed surgery group were cardiac surgeries, with about $53 \%$ of the patients in the mixed group undergoing cardiac surgery in addition to other surgery). The matched cohorts with $n=1506$ patients each showed no significant differences in the baseline characteristics except a higher age, SAPS II score, and delirium score in the finer filter cohort (Table 1)

\section{Primary endpoint}

We found no significant difference in the incidence rate of severe vasoplegia between the fine filter and the control filter cohort $(21.0 \%$ vs $19.6 \%$; risk ratio $(95 \% \mathrm{CI})=$ 1.07 (0.93-1.23), $P>0.20$ for non-parametric Fisher test; $P>0.20$ for Wald test on regression model with odds ratio $(95 \% \mathrm{CI})=1.05(0.87-1.27))$ (Table 2), although the rate of patients receiving norepinephrine in the fine filter cohort $(82.9 \%$ vs $65.4 \% ; P<0.01)$ and the maximum rate of norepinephrine per patient in the fine filter cohort were significantly higher (median 0.09 vs $0.05 ; P<0.01$ ) (Table 2). Interestingly, the calculated rate of vasoplegia in both cohorts was here about twice as high as assumed in the SAP. The additionally analysed methylene blue rate was not significantly different between the two cohorts $(9.8 \%$ vs $10.2 \% ; P>0.20)$ (Table 2$)$.

\section{Secondary endpoints}

The fine filter cohort showed significantly improved lung function by a higher minimal Horowitz index (median
206 vs $191 ; P=0.04)$ and lower ARDS score (median 1 vs $2 ; P=0.01$ ) (Table 3 ). The maximum creatinine value (median 1.09 vs $1.12 ; P=0.19$ ) and our modified AKI score rate $(11.8 \%$ vs $13.7 \%$; $P=0.11)$ showed no significant difference between the two cohorts. No difference was found for delirium score or multi-organ dysfunction scores in the non-parametric analysis but obtained for delirium score $(P<0.01)$ and SAPS II score $(P<0.01)$ in the additional multivariate analysis when taking into account also the baseline values, age, sex, and surgery group (Table 3).

The maximum IL-6 value as marker for inflammation was significantly lower in the fine filter cohort (median of 471.5 vs $540.5 \mathrm{ng} / \mathrm{l} ; \quad P=0.01$ ) (Table 4). We hypothesised that specific subgroups of patients with a reduced immune response might especially benefit from the use of in-line filtration with finer 0.2 and $1.2 \mu \mathrm{m}$ filters. Therefore, we conducted an additional subgroup analysis for cardiac surgery group patients only and all other remaining surgery group patients, regarding their IL- 6 values. We obtained the following results in the additional subgroup analysis: $P=0.02$ and $\mathrm{MW}=0.46(0.43-0.49)$ for the only cardiac surgery group vs $P=0.17$ and $\mathrm{MW}=0.48(0.45-0.50)$ for the remaining patient group. This showed a lower IL-6 value for the finer filter cohort within the cardiac surgery subgroup. In the other subgroup, the difference was not significant, although the tendency of the MW effect estimator shows again a lower Il-6 value for the finer filter. We compared the effect estimators between the only cardiac and the remaining subgroup (with the appropriate chi-square test for AUCs, using the estimator and its standard deviation) and obtained no statistically significant different result $(P>0.20)$. Only a higher number of patients might reveal the estimated significant difference here. In addition, we assessed the IL- 6 kinetics by comparing the period including IL-6 maximum value. We obtained as typical peak time a median of $3(0-12) \mathrm{h}$ for the fine filter cohort and $3(0-13) \mathrm{h}$ for the control filter cohort (Mann-Whitney test, $P=0.19, \mathrm{MW}=0.49(0.47-0.51)$ ). In this respect, the difference between the two cohorts cannot be explained by different IL- 6 kinetics but more likely by the actual maximal value.

The length of both cumulated ICU (median 1.2 vs 1.7 days; $P<0.01$ ) and hospital stay (median 14.0 vs 14.8; $P=0.01$ ) was significantly shorter in the fine filter cohort. Considering the length of stay as a competing risk for death, analysis showed a significantly reduced length of stay in the fine filter cohort also for the survivors (ICU: median 1.0 vs 1.3 days; $P<0.01$; hospital stay: 14.0 vs $14.4 ; \quad P=0.01$ ) (Table 5). 
Table 1 Baseline characteristics of patients (propensity score matched)

\begin{tabular}{|c|c|c|c|}
\hline & Fine filter cohort $(n=1506)$ & Control filter cohort $(n=1506)$ & $P$ value $^{a}$ \\
\hline Age (years) & $68(58.0-75), 65.7 \pm 0.3$ & $66(57-74), 63.9 \pm 0.3$ & $\begin{array}{l}\text { Approximate match, } P<0.01 \text {, } \\
\text { MW } 0.54(0.52-0.56)\end{array}$ \\
\hline Male sex $(n ; \%)$ & $1081 ; 71.8 \%$ & $1081 ; 71.8 \%$ & Exact match, $P=1.00$ \\
\hline Surgery groups $(n ; \%)$ & & & Exact match, $P=1.00$ \\
\hline No surgery & $204 ; 13.5 \%$ & $204 ; 13.5 \%$ & \\
\hline Dermatology, ophthalmology & $4 ; 0.3 \%$ & $4 ; 0.3 \%$ & \\
\hline Neurosurgery & $1 ; 0.1 \%$ & $1 ; 0.1 \%$ & \\
\hline Otorhinolaryngology & $16 ; 1.1 \%$ & $16 ; 1.1 \%$ & \\
\hline Thoracic & $14 ; 0.9 \%$ & $14 ; 0.9 \%$ & \\
\hline Cardiac & $617 ; 41.0 \%$ & $617 ; 41.0 \%$ & \\
\hline Vascular & $48 ; 3.2 \%$ & $48 ; 3.2 \%$ & \\
\hline Visceral and endocrine & $46 ; 3.1 \%$ & $46 ; 3.1 \%$ & \\
\hline Urology & $12 ; 0.8 \%$ & $12 ; 0.8 \%$ & \\
\hline Gynaecology & $1 ; 0.1 \%$ & $1 ; 0.1 \%$ & \\
\hline Obstetric & $3 ; 0.2 \%$ & $3 ; 0.2 \%$ & \\
\hline Oral and maxillofacial & $2 ; 0.1 \%$ & $2 ; 0.1 \%$ & \\
\hline Trauma/orthopaedic & $32 ; 2.1 \%$ & $32 ; 2.1 \%$ & \\
\hline Other surgery & $1 ; 0.1 \%$ & $1 ; 0.1 \%$ & \\
\hline Mixed & $505 ; 33.5 \%$ & $505 ; 33.5 \%$ & \\
\hline Discarded for matching (n) & 115 & 88 & \\
\hline Initial SOFA score ${ }^{b}$ & $8(6-11)$ & $8(5-11)$ & $>0.20$ \\
\hline Initial SAPS $\|^{C}$ & $46(33.5-58)$ & $41(30-56)$ & $<0.01$, MW $0.56(0.52-0.59)$ \\
\hline Initial TISS-10 & $18(14-26)$ & $21(14-26)$ & $>0.20$ \\
\hline Initial TISS-28 & $39(33-45)$ & $38(32.5-45)$ & 0.17 \\
\hline Initial Horowitz index ${ }^{f}$ & $317(234-393)$ & $314(232-383)$ & $>0.20$ \\
\hline Initial creatinine value $(\mathrm{mg} / \mathrm{dll})^{9}$ & $0.90(0.72-1.17)$ & $0.90(0.72-1.20)$ & $>0.20$ \\
\hline Initial delirium score ${ }^{\text {h }}$ & $2(0-5)$ & $1(0-3)$ & $<0.01$, MW $0.55(0.51-0.59)$ \\
\hline Initial interleukin-6 value $\left(\mathrm{ng} / \mathrm{l}^{\mathrm{i}}\right.$ & $284.2(135.9-605.2)$ & $284.2(131.2-672.0)$ & $>0.20$ \\
\hline
\end{tabular}

This table shows the distribution of subjects between the fine filter and control filter cohort by demographic characteristics, surgery category, and baselines for multi-organ scores and for chosen laboratory values at admission. Age, delirium score, and SAPS II at admission were significantly worse for the fine filter cohort Data are presented as the mean \pm standard error, as the median (first quartile-third quartile), as the percentage rates (with $95 \%$ confidence intervals), or as the number $(n)$ of patients, where indicated

${ }^{a} P$ values were calculated using the Wilcoxon-Mann-Whitney $U$ test for equality of means, Pearson's chi-square test, or Fisher's exact test, as appropriate. Odds ratios or Mann-Whitney effect estimators (Delong method for AUC between 0 and 1 ) are provided as appropriate and only if the $P$ value is significant

${ }^{\mathrm{b}}$ Available patients with SOFA score (\%): 30.2 (fine filter) and 39.6 (control filter)

'Available patients with SAPS II score (\%): 36.6 (fine filter) and 44.4 (control filter)

${ }^{\mathrm{d}}$ Available patients with TISS-10 score (\%): 32.3 (fine filter) and 43.0 (control filter)

${ }^{\text {e}}$ Available patients with TISS-28 score (\%): 32.3 (fine filter) and 43.0 (control filter)

${ }^{f}$ Available patients with Horowitz index (\%): 86.8 (fine filter) and 72.8 (control filter)

${ }^{9}$ Available patients with creatinine value before dialysis (\%): 99.1 (fine filter) and 99.1 (control filter)

${ }^{\mathrm{h}}$ Available patients with delirium score (\%): 20.5 (fine filter) and 52.5 (control filter)

'Available patients with interleukin-6 value (\%): 98.4 (fine filter) and 98.2 (control filter)

The overall in-hospital mortality rate was comparable $(13.1 \%$ vs $14.1 \% ; P>0.20)$. Similarly, the 28 -day mortality was comparable $(8.8 \%$ vs $10.3 \% ; P=0.19)$ (Table 5).

Analysing routine ICD-10 codes, typical in-hospital complications were significantly lower in the fine filter cohort (pneumonia $11.4 \%$ vs $14.4 \%, P=0.02$, and sepsis
9.6\% vs $12.2 \%, P=0.03$ ) (Table 5 ). For rarer complications such as ischemic stroke $(1.7 \%$ vs $1.7 \% ; P>0.20)$ and myocardial infarction $(2.3 \%$ vs $1.4 \% ; P=0.06)$, no significant difference was found (Table 5) between the two cohorts. In addition, a composite endpoint including in-hospital mortality, myocardial infarction, ischemic stroke, pneumonia, and sepsis showed no significant 
Table 2 Primary outcome parameters (vasoplegia)

\begin{tabular}{|c|c|c|c|c|}
\hline & Fine filter cohort $(n=1506)$ & Control filter cohort $(n=1506)$ & $P$ value $^{a}$ & $P$ value ${ }^{b}$ \\
\hline Vasoplegia (n; \%) & $316 ; 21.0 \%$ (19.0-23.1\%) & $295 ; 19.6 \%$ (17.6-21.7\%) & $>0.20$, RR 1.07 (0.93-1.23) & $\begin{array}{l}>0.20, \text { OR } 1.05 \\
(0.87-1.27)\end{array}$ \\
\hline $\begin{array}{l}\text { Maximum rate of } \\
\text { norepinephrine }(\mu \mathrm{g} / \mathrm{kg} / \mathrm{min})\end{array}$ & $0.09(0.03-0.23), 0.16 \pm 0.01$ & $0.05(0.00-0.20), 0.14 \pm 0.01$ & $<0.01$, MW $0.58(0.56-0.60)$ & $<0.01$ \\
\hline $\begin{array}{l}\text { Patients receiving } \\
\text { norepinephrine }(n ; \%)\end{array}$ & $1249 ; 82.9 \%$ (80.9-84.8\%) & 1000; 66.4\% (64.0-68.8\%) & $<0.01, \operatorname{RR} 1.25$ (1.20-1.30) & $\begin{array}{l}<0.01, \text { OR } 1.17 \\
(1.14-1.21)\end{array}$ \\
\hline $\begin{array}{l}\text { Patients receiving } \\
\text { methylene blue }(n ; \%)\end{array}$ & $147 ; 9.8 \%(8.3-11.4 \%)$ & $153 ; 10.2 \%(8.7-11.8 \%)$ & $>0.20$ & $>0.20$ \\
\hline
\end{tabular}

This table shows the occurrence rate of the primary endpoint vasoplegia and the total amount of chosen vasopressor drugs between the fine filter and control filter group. Rate of vasoplegia was not significantly different between the fine filter and the control filter cohort

Data are presented as the mean \pm standard error, as the median (first quartile-third quartile), as the percentage rates (with $95 \%$ confidence intervals), or as the number $(n)$ of patients, where indicated

${ }^{a} P$ values were calculated using the Wilcoxon-Mann-Whitney $U$ test for equality of means, Pearson's chi-square test, or Fisher's exact test, as appropriate. Risk ratios or Mann-Whitney effect estimators (Delong method for AUC) are provided as appropriate

${ }^{b} P$ values were calculated using the Wald test. The regression model includes cohort, age, sex, and surgery as regression variables. Odds ratios are provided if appropriate and if the $P$ value is significant

difference between the two cohorts $(26.9 \%$ vs $29.0 \%$; $P>0.20$ ) (Table 5).

\section{Discussion}

In our propensity-matched cohort analysis, the routine use of finer 0.2 and $1.2 \mu \mathrm{m}$ in-line filters compared to larger $5 \mu \mathrm{m}$ control filters had no beneficial effects on the rate of catecholamines and on AKI, but was associated with decreased markers of inflammation and a decreased risk of respiratory dysfunction, sepsis, pneumonia, and slightly reduced length of ICU and inhospital stay. In this respect, we postulate a clinical relevance for patients on intensive care units.

Microparticle-contaminated infusions and drugs may have adverse effects in critically ill patients and are suspected to be responsible for unspecific inflammation that might lead to different organ manifestations. Postmortem studies have demonstrated that a high amount of particles enters the patient if no in-line filters have been used. This might already be challenging for a healthy patient but could be even worse for severely ill patients. So far, no significant benefits of finer 0.2 and $1.2 \mu \mathrm{m}$ in-line filters in comparison to no filters were found in a previous adult study [35].

Recent studies including critically ill children and newborns instead did show a significant reduction of organ dysfunction by using in-line filters (finer $0.2 \mu \mathrm{m}$ for aqueous solutions and $1.2 \mu \mathrm{m}$ for lipid-containing mixtures in the filter cohort [9-11] as well as only $0.2 \mu \mathrm{m}$ for aqueous solutions but no filters for lipid-containing mixtures in the filter cohort [12]). Interestingly, all mentioned studies used no filter in the control cohort compared to the larger $5 \mu \mathrm{m}$ filter as intervention but that was used in our control cohort.

We initially chose to investigate a possible and clinical important manifestation of inflammation, vascular dilatation, leading to severe vasoplegia. However, vasoplegia is a complex syndrome and we tried to identify this by simply choosing high dose norepinephrine as a surrogate parameter. As a limitation, norepinephrine alone might not be the best surrogate for vasoplegia, as other reasons on a surgical ICU such as ongoing blood loss and other forms of shock might have an additional effect on our readout system.

We explain the positive outcome of some secondary endpoints by the fact that these data are also theoretically able to model manifestations of inflammation. It has to be stated that all our readout systems do not have a proven direct link to microparticle infusion. To the best of our knowledge, the underlying mechanisms are not yet understood. The clinical data at this moment only support the hypothesis that infused particles somehow augment a systemic inflammation response. Therefore, specific subgroups of patients with a reduced immune response might especially benefit from the use of in-line filtration with finer 0.2 and $1.2 \mu \mathrm{m}$ filters. Our additional subgroup analysis showing significantly better results for IL-6 values for the fine filter cohort within the only cardiac surgery group supports this assumption, comparable to results of Sasse et al. [11]. Exaggerated inflammation levels after cardiopulmonary bypass surgery are a well-known phenomenon, and additional triggers of inflammation should be avoided if possible. Based on our additional basic IL-6 kinetics analysis on all included patients, we conclude furthermore that the beneficial effects of the finer in-line filters are more likely given by reducing the maximal IL-6 value than by reducing the peak time to maximal inflammation.

Based on these data, the benefits for (finer) filters will remain uncertain. We hope that prospective studies will address the theory of microparticle-induced inflammation and evaluate the effects of the finer filters. 
Table 3 Secondary outcome parameters (multiple-organ dysfunction, lung dysfunction, acute kidney injury, brain dysfunction)

\begin{tabular}{|c|c|c|c|c|}
\hline & $\begin{array}{l}\text { Fine filter cohort } \\
(n=1506)\end{array}$ & $\begin{array}{l}\text { Control filter cohort } \\
(n=1506)\end{array}$ & $P$ value $^{a}$ & $P$ value $^{\mathrm{b}}$ \\
\hline \multicolumn{5}{|l|}{ Multi-organ dysfunction } \\
\hline Maximal SOFA score & $9(6-13)$ & $10(6-13)$ & $>0.20$ & 0.15 \\
\hline Maximal SAPS II score & $53(39-71)$ & $52(34-72.25)$ & $>0.20$ & $<0.01^{c}$ \\
\hline Maximal TISS-10 score & $23(18-29.75)$ & $26(18-30)$ & 0.08 & 0.06 \\
\hline Maximal TISS-28 score & $44(36.25-51)$ & $45(36-51)$ & $>0.20$ & 0.12 \\
\hline \multicolumn{5}{|l|}{ Lung dysfunction } \\
\hline Minimal Horowitz index & $206(119-290)$ & $191(104.75-280)$ & $\begin{array}{l}0.04, \mathrm{MW} 0.52 \\
(0.50-0.55)\end{array}$ & 0.02 \\
\hline ARDS score & $1(1-2)$ & $2(1-2)$ & $\begin{array}{l}0.01, \mathrm{MW} 0.47 \\
(0.45-0.49)\end{array}$ & $<0.01$ \\
\hline 0, no $\operatorname{ARDS}(n ; \%)$ & $296 ; 22.6 \%$ & $215 ; 19.6 \%$ & & \\
\hline 1 , mild ARDS $(n ; \%)$ & $376 ; 28.8 \%$ & $302 ; 27.6 \%$ & & \\
\hline 2 , moderate ARDS $(n ; \%)$ & $377 ; 28.8 \%$ & $324 ; 29.6 \%$ & & \\
\hline 3 , severe $\operatorname{ARDS}(n ; \%)$ & $258 ; 19.7 \%$ & $255 ; 23.3 \%$ & & \\
\hline \multicolumn{5}{|l|}{ Heart/lung dysfunction (ECMO) } \\
\hline Patients on ECMO $(n ; \%)$ & $30 ; 2.0 \%(1.3-2.8 \%)$ & $38 ; 2.5 \%(1.8-3.4 \%)$ & $>0.20$ & $>0.20$ \\
\hline Cumulative duration (days) without first day & $4.5(1.4-7.5)$ & $6.8(4.8-12.4)$ & $\begin{array}{l}0.01, \mathrm{MW} 0.33 \\
(0.19-0.46)\end{array}$ & 0.09 \\
\hline Cumulative duration (days) & $5.5(2.4-8.5)$ & $8.2(5.8-13.4)$ & $\begin{array}{l}0.02, \mathrm{MW} 0.33 \\
(0.20-0.47)\end{array}$ & 0.15 \\
\hline \multicolumn{5}{|l|}{ Acute kidney injury (AKI) } \\
\hline Maximal creatinine value before dialysis (mg/dl) & $1.09(0.84-1.74)$ & $1.12(0.84-1.83)$ & 0.19 & $<0.01^{\mathrm{d}}$ \\
\hline Maximal creatinine value before dialysis per interval $(n ; \%)$ & $626 ; 41.9 \%$ & $600 ; 40.2 \%$ & - & - \\
\hline $0.00-1.00 \mathrm{mg} / \mathrm{dl}$ & $578 ; 38.7 \%$ & $574 ; 38.5 \%$ & & \\
\hline $1.01-2.00 \mathrm{mg} / \mathrm{dl}$ & $169 ; 11.3 \%$ & $167 ; 11.2 \%$ & & \\
\hline $2.01-3.00 \mathrm{mg} / \mathrm{dl}$ & $63 ; 4.2 \%$ & $79 ; 5.3 \%$ & & \\
\hline $3.01-4.00 \mathrm{mg} / \mathrm{dl}$ & $44 ; 2.9 \%$ & $51 ; 3.4 \%$ & & \\
\hline $4.01-6.00 \mathrm{mg} / \mathrm{dl}$ & $13 ; 0.9 \%$ & $20 ; 1.3 \%$ & & \\
\hline \multicolumn{5}{|l|}{$>6.00 \mathrm{mg} / \mathrm{dl}$} \\
\hline $\begin{array}{l}\text { Modified AKIN score rate (no AKI/mild AKI vs moderate } \\
\text { AKI/severe AKI) }\end{array}$ & $11.8 \%(10.2-13.5 \%)$ & $13.7 \%(12.0-15.5 \%)$ & 0.11 & 0.06 \\
\hline Modified AKIN score per classes & $1(1-1)$ & $1(1-1)$ & 0.11 & 0.05 \\
\hline 0, no $A K I(n ; \%)$ & $1 ; 0.1 \%$ & $2 ; 0.1 \%$ & & \\
\hline 1 , mild AKI $(n ; \%)$ & $1316 ; 88.1 \%$ & $1284 ; 86.1 \%$ & & \\
\hline 2 , moderate AKI $(n ; \%)$ & $92 ; 6.2 \%$ & $101 ; 6.8 \%$ & & \\
\hline 3 , severe AKI $(n ; \%)$ & $84 ; 5.6 \%$ & $104 ; 7.0 \%$ & & \\
\hline Dialysis rate $(n ; \%)$ & $235 ; 15.6 \%(13.8-17.5 \%)$ & $247 ; 16.4 \%(14.6-18.4 \%)$ & $>0.20$ & $>0.20$ \\
\hline \multicolumn{5}{|l|}{ Brain dysfunction } \\
\hline Maximal delirium score & $4(1-7)$ & $3(1-6)$ & $>0.20$ & $<0.01^{\mathrm{e}}$ \\
\hline
\end{tabular}

This table shows the values of the secondary endpoints multi-organ, heart, lung, and brain dysfunction between the fine filter and control filter cohort. Lung (Horowitz value and ARDS score) dysfunction was significantly better for the fine filter cohort

Data are presented as the median (first quartile-third quartile), as the percentage rates (with $95 \%$ confidence intervals), or as the number ( $n$ ) of patients, where indicated

a $P$ values were calculated using the Wilcoxon-Mann-Whitney $U$ test for equality of means, Pearson's chi-square test, or Fisher's exact test, as appropriate. Mann-Whitney effect estimators (Delong method for AUC) and risk ratios are provided as appropriate and if the $P$ value is significant ${ }^{b} P$ values were calculated using the Wald test. The regression model includes baseline, cohort, age, sex, and surgery as regression variables. Odds ratios are provided if appropriate and if the $P$ value is significant

${ }^{c}$ Maximal SAPS II score was better for the fine filter cohort

${ }^{\mathrm{d}}$ Maximal creatinine value was better for the fine filter cohort

e Maximal delirium score was better for the fine filter cohort 
Table 4 Secondary outcome parameters (inflammation, cytokines)

\begin{tabular}{|c|c|c|c|c|}
\hline & Fine filter cohort $(n=1506)$ & Control filter cohort $(n=1506)$ & $P$ value $^{\mathrm{a}}$ & $P$ value \\
\hline \multicolumn{5}{|l|}{ Inflammation } \\
\hline Maximal interleukin-6 value (ng/l) & $471.5(258.8-1062.8)$ & $540.5(284.5-1147.5)$ & 0.01, MW $0.47(0.45-0.49)$ & 0.01 \\
\hline Maximal interleukin-6 per interval ( $n$; \%) & & & - & - \\
\hline $0.0-50.0 \mathrm{ng} / \mathrm{l}$ & $30 ; 2.0 \%$ & $39 ; 2.6 \%$ & & \\
\hline $50.1-200.0 \mathrm{ng} / \mathrm{l}$ & $188 ; 15.4 \%$ & $188 ; 12.7 \%$ & & \\
\hline $200.1-500.00 \mathrm{ng} / \mathrm{l}$ & $519 ; 35.0 \%$ & $474 ; 32.0 \%$ & & \\
\hline > $500.00 \mathrm{ng} / \mathrm{l}$ & $726 ; 47.6 \%$ & $778 ; 52.6 \%$ & & \\
\hline
\end{tabular}

This table shows the values of the secondary endpoint inflammation between the fine filter and control filter cohort. Interleukin- 6 was significantly better for the fine filter cohort

Data are presented as the median (first quartile-third quartile), as the percentage rates (with $95 \%$ confidence intervals), or as the number ( $n$ ) of patients, where indicated

${ }^{a} P$ values were calculated using the Wilcoxon-Mann-Whitney $U$ test for equality of mean. Mann-Whitney effect estimators (Delong method for AUC) are provided if the $P$ value is significant

${ }^{\mathrm{b}} P$ values were calculated using the Wald test. The regression model includes baseline, cohort, age, sex, and surgery as regression variables. Odds ratios are provided if appropriate and if the $P$ value is significant

\section{Limitations}

Our study had several limitations. As the study was retrospective and depended on an automated readout system, no additional data could be gathered afterwards. Besides that, being a mono-centre study, composition of patients could vary in other centres but we assume, as many results hold also for various subgroups, that this difference is not essential.
Furthermore, our analysis includes mainly surgical ICU patients. The accuracy of the encoded routine ICD-10 diagnoses in general has not been assessed, but we assume that for this short time period of 2 years, the coding pattern did not change relevantly. A simple intraoperative factor we cannot statistically exclude and which might be a potential bias could be seen in different surgical and anaesthesiologic teams

Table 5 Secondary outcome parameters (length of stay, mortality, in-hospital complications, and morbidity rates)

\begin{tabular}{|c|c|c|c|c|}
\hline & $\begin{array}{l}\text { Fine filter cohort } \\
(n=1506)\end{array}$ & $\begin{array}{l}\text { Control filter cohort } \\
(n=1506)\end{array}$ & $P$ value ${ }^{a}$ & $P$ value ${ }^{b}$ \\
\hline \multicolumn{5}{|l|}{ Length of stay } \\
\hline ICU stay (days) & $1.2(0.6-4.9)$ & $1.7(0.8-6.9)$ & $<0.01$, MW $0.46(0.44-0.48)$ & 0.02 \\
\hline ICU stay survivors (days) & $1.0(0.6-3.9)$ & $1.3(0.7-5.2)$ & $<0.01$, MW $0.46(0.44-0.49)$ & $<0.01$ \\
\hline ICU stay non-survivors (days) & $4.9(2.0-15.3)$ & $7.2(2.5-17.5)$ & 0.11 & $>0.20$ \\
\hline In-hospital stay (days) & $14.0(9.2-22.2)$ & $14.8(10.0-26.8)$ & 0.01, MW $0.47(0.45-0.49)$ & $>0.20$ \\
\hline In-hospital stay survivors (days) & $14.0(9.2-24.0)$ & $14.4(10.1-26.2)$ & 0.01, MW $0.46(0.44-0.49)$ & 0.18 \\
\hline In-hospital stay non-survivors (days) & $14.2(5.6-36.0)$ & $16.0(8.2-32.4)$ & $>0.20$ & $>0.20$ \\
\hline \multicolumn{5}{|l|}{ Mortality } \\
\hline In-hospital 28-day mortality rate ( $n$; \%) & $133 ; 8.8 \%(7.4-10.4 \%)$ & $155 ; 10.3 \%(8.8-11.9 \%)$ & 0.19 & 0.05 \\
\hline In-hospital mortality rate $(n ; \%)$ & $198 ; 13.1 \%(11.5-15.0 \%)$ & $213 ; 14.1 \%(12.4-16.0 \%)$ & $>0.20$ & 0.15 \\
\hline \multicolumn{5}{|l|}{ In-hospital complications and morbidities } \\
\hline Myocardial infarction $(n ; \%)$ & $26 ; 1.7 \%(1.1-2.5 \%)$ & $25 ; 1.7 \%(1.1-2.4 \%)$ & $>0.20$ & $>0.20$ \\
\hline Ischemic stroke $(n ; \%)$ & $35 ; 2.3 \%(1.6-3.2 \%)$ & $21 ; 1.4 \%(0.9-2.1 \%)$ & 0.08 & 0.06 \\
\hline Pneumonia $(n ; \%)$ & $172 ; 11.4 \%(9.9-13.1 \%)$ & $217 ; 14.4 \%(12.7-16.3 \%)$ & 0.02, RR $0.79(0.66-0.96)$ & $<0.01$, OR $0.73(0.58-0.91)$ \\
\hline Sepsis $(n ; \%)$ & $145 ; 9.6 \%(8.2-11.2 \%)$ & $183 ; 12.2 \%(10.5-13.9 \%)$ & 0.03, RR $0.79(0.64-0.97)$ & 0.01 , OR $0.73(0.57-0.94)$ \\
\hline Composite endpoint $^{\complement}(n ; \%)$ & $405 ; 26.9 \%(24.7-29.2 \%)$ & $437 ; 29.0 \%(26.7-31.4 \%)$ & $>0.20$ & 0.05, OR $0.84(0.71-1.00)$ \\
\hline
\end{tabular}

This table shows the values of the co-secondary endpoints length of stay, mortality, and perioperative complications/morbidities between the fine filter and the control filter cohort. Length of ICU and in-hospital stay, pneumonia, and sepsis rate were significantly better for the fine filter cohort

Data are presented as the median (first quartile-third quartile), as the percentage rates (with $95 \%$ confidence intervals), or as the number ( $n$ ) of patients, where indicated

${ }^{a} P$ values were calculated using the Wilcoxon-Mann-Whitney $U$ test for equality of means, Pearson's chi-square test, or Fisher's exact test, as appropriate. MannWhitney effect estimator (Delong method for AUC) and risk ratios are provided as appropriate and if the $P$ value is significant

${ }^{\mathrm{b}} P$ values were calculated using the Wald test, as appropriate. The regression model includes cohort, age, sex, and surgery as regression variables. Odds ratios are provided if appropriate and if the $P$ value is significant

'In-hospital mortality, myocardial infarction, ischemic stroke, pneumonia, and sepsis 
performing the procedures. Therefore, especially, fluid management regarding type and amount could differ between the time periods. Unfortunately, we cannot normalise the amount of fluids administered to body weight, as we do not have all information to types and volumes given. But we assume due to equal pair matching in each cohort that the received fluids were approximately the same, given the high number of patients which help avoiding bigger random effects. At any time period, mostly crystalloid fluids were used in general. As we did not analyse data regarding urine output, we have to acknowledge that we lose a significant percentage of AKI cases. Furthermore, we do not have additional data about ventilation length and patients' oxygenation.

Advantages of our propensity-matched study design are mainly statistical: first, the large number of potentially interesting endpoints being investigated and the high number of patients included that did not need to be enrolled, and second, the retrospective approach using routine data which saved time, staff, and costs. Due to the fact that we matched the cohorts equally in number, age, sex, and surgery discipline, at least no bias due to these patient characteristics should have arisen. However, we cannot exclude mild differences regarding other potentially important characteristics such as comorbidities.

\section{Conclusions}

We suggest that in-line filtration with finer 0.2 and $1.2 \mu \mathrm{m}$ filters could reduce systemic inflammation and maybe morbidity in critically ill adult patients and hence improve safety of intensive care therapy. But further prospective studies might be warranted to investigate these effects in detail.

\begin{abstract}
Abbreviations
AKI: Acute kidney injury; AKIN: Acute Kidney Injury Network; ARDS: Acute respiratory distress syndrome; AUC: Area under the ROC curve; CRF/ eCRF: Case report forms/electronical case report forms; ECLIA: Electrochemiluminescence immunoassay; ECMO: Extracorporeal membrane oxygenation; ICDSC: The Intensive Care Delirium Screening Checklist; ICU: Intensive care unit; KDIGO: Kidney Disease Improving Global Outcomes; MW: Mann-Whitney U estimator; OR: Odds ratio; RR: Risk ratio; SAP: Statistical analysis plan; SAPS: Simplified Acute Physiology Score; SE: Standard error; SIRS: Systemic inflammatory response syndrome; SOFA: Sequential Organ Failure Assessment score; TISS: Therapeutic Intervention Scoring System
\end{abstract}

\section{Acknowledgements}

We thank Mrs. Annette Bartholmes (Division of Software and Information Systems, Department of Information and Communication Technology, University Hospital Frankfurt) for kindly providing us additional data.

\section{Authors' contributions}

ES, PM, HN, and KZ wrote the manuscript. EH, KA, SL, and PH critically read the manuscript. $R E$ read the manuscript. $K Z_{i}, P M$, and $E H$ designed the study and the statistical analysis plan. HN and ES critically reviewed the study and the statistical analysis plan. ES performed the statistical analysis. EH provided senior statistical support and critically reviewed the results of the statistical analysis. RE contributed to the initial data sampling and assisted in the preliminary data analysis. PM, HN, and KZ evaluated and critically revised the medical results of the statistical analysis. KA provided all the data. All authors read and approved the final manuscript.

\section{Funding}

The study was conducted with the internal department funding only.

\section{Availability of data and materials}

The data that support the findings of this study are available from the corresponding author upon reasonable request.

\section{Ethics approval and consent to participate}

The study was approved by the local ethics committee (Goethe University Frankfurt am Main, ref. 8/14 from 30 January 2014), which waived the need for informed consent.

\section{Consent for publication}

Not applicable.

\section{Competing interests}

The authors declare that they have no competing interests.

\section{Author details}

${ }^{1}$ Department of Anaesthesiology, Intensive Care Medicine and Pain Therapy, University Hospital Frankfurt, Frankfurt am Main, Germany. ${ }^{2}$ Institute of Biostatistics and Mathematical Modelling, Department of Medicine, Goethe University Frankfurt, Frankfurt am Main, Germany. ${ }^{3}$ Department of Anaesthesiology, University Hospital Wuerzburg, Wuerzburg, Germany. ${ }^{4}$ Division of Software and Information Systems, Department of Information and Communication Technology, University Hospital Frankfurt, Frankfurt am Main, Germany.

Received: 12 February 2019 Accepted: 20 September 2019

Published online: 22 November 2019

\section{References}

1. Hartenauer U, Hofmann W, Wierschem G, Gercken G, Winzer H. Entstehung und Verhütung bakterieller Kontamination von Infusionssystemen bei parenteraler Ernährung (Untersuchungen an IntensivbehandlungsPatienten). 25 Jahre DGAl. Jahrestagung in Würzburg 1978.

Anaesthesiologie und Intensivmedizin. Anaesthesiology and Intensive Care Medicine. Springer Verlag. 1980; 205-211.

2. Mehrkens HH, Klaus E, Schmitz JE. Possibilities of material contamination due to additional injections. Klin Anasthesiol Intensivther. 1977;14:106-13.

3. Oie S, Kamiya A. Particulate and microbial contamination in in-use admixed parenteral nutrition solutions. Biol Pharm Bull. 2005;28(12):2268-70.

4. Hellinger A, Piotrowski J, Konerding MA, Burchard WG, Doetsch N, Peitgen K, Erhard J, Reidemeister JC. Impact of particulate contamination in crystalloid cardioplegic solutions: studies by scanning and transmission electron microscopy. Thorac Cardiovasc Surg. 1997;45:20-6.

5. Ernst C, Keller M, Eckstein J. Mikro-Infusionsfilter und Partikelgehalt von Parenteralia. In-situ-Partikelmessung für verschiedene Infusionsszenarien mittels Flüssigkeitspartikelzähler - eine Machbarkeitsstudie. Micro-infusion filters and particulate matter in injections - in-situ particle measurement for miscellaneous applications of infusions by using liquid particle counters - a feasibility study. Pharmazeutische Industrie. 2012;74(12):2009-20.

6. Perez M, Décaudin B, Abou Chahla W, Nelken B, Storme L, Masse M, Barthélémy C, Lebuffe G, Odou P. Effectiveness of in-line filters to completely remove particulate contamination during a pediatric multidrug infusion protocol. Sci Rep. 2017:8:7714.

7. Ball P. Intravenous in-line filters: filtering the evidence. Curr Opin Clin Nutr Metab Care. 2003;6(3):319-25.

8. Bethune K, Allwood M, Grainger C, Wormleighton C. Use of filters during the preparation and administration of parenteral nutrition: position paper and guidelines prepared by a British pharmaceutical nutrition cohort working party. Nutrition. 2001;17:403-8.

9. Jack T, Boehne M, Brent BE, Hoy L, Köditz H, Wessel A, Sasse M. In-line filtration reduces severe complications and length of stay on pediatric intensive care unit: a prospective, randomized, controlled trial. Intensive Care Med. 2012;38:1008-16. 
10. Boehne M, Jack T, Köditz H, Seidemann K, Schmidt F, Abura M, Bertram H, Sasse M. In-line filtration minimizes organ dysfunction: new aspects from a prospective, randomized, controlled trial. BMC Pediatr. 2013;13(1):21.

11. Sasse M, Dziuba F, Jack T, Köditz H, Kaussen T, Bertram H, Beerbaum P, Boehne $M$. In-line filtration decreases systemic inflammatory response syndrome, renal and hematologic dysfunction in pediatric cardiac intensive care patients. Pediatr Cardiol. 2015;36(6):1270-8.

12. Van Lingen RA, Baerts W, Marquering AC, Ruijs GJ. The use of in-line intravenous filters in sick newborn infants. Acta Paediatr. 2004;93: 658-62.

13. Foster JP, Richards R, Showell MG, Jones $L$ J. Intravenous in-line filters for preventing morbidity and mortality in neonates. Cochrane Database Syst Rev. 2015:8:CD005248.

14. Newall F, Ranson K, Robertson J. Use of in-line filters in pediatric intravenous therapy. Intravenous Nursing. 1998;21(3):166-70.

15. O'Grady NP, Alexander M, Dellinger EP, Gerberding JL, Heard SO, Maki DG, Masur H, McCormick RD, Mermel LA, Pearson ML, Raad II, Randolph A, Weinstein RA. Guidelines for the prevention of intravascular catheter-related infections. US Pediatrics. 2002;110(5):e51.

16. O'Grady NP, Alexander M, Burns LA, Dellinger EP, Garland J, Heard SO, Lipsett PA, Masur H, Mermel LA, Pearson ML, Raad II, Randolph AG, Rupp ME, Saint S. Healthcare Infection Control Practices Advisory Committee. Guidelines for the prevention of intravascular catheter-related infections. Centers Dis Prev. 2011;52(9):e162e193.

17. Walpot H, Franke RP, Burchard WG, Agternkamp C, Müller FG, Mittermayer C, Kalff G. Particulate contamination of infusion solutions and drug additives in the framework of long-term intensive therapy. 1 Energy dispersion electron images in the scanning electron microscope-REM/EDX. Anaesthesist. 1989:38:544-8.

18. Walpot H, Franke RP, Burchard WG, Agternkamp C, Müller FG, Mittermayer $C$, Kalff G. Particulate contamination of infusion solutions and drug additives in the framework of long-term intensive therapy. 2: an animal model. Anaesthesist. 1989;38:617-21.

19. Jack T, Brent BE, Boehne M, Muller M, Sewald K, Braun A, Wessel A, Sasse M. Analysis of particulate contaminations of infusion solutions in a pediatric intensive care unit. Intensive Care Med. 2010;36(4):707-11.

20. CIRS-AINS Spezial. Partikelkontamination nach dem Aufziehen von Arzneimitteln - Ein relevantes aber lösbares Problem. Anästh Intensivmed. 2013;54:607-11 Reprint of original article: Günther W, Hahnenkamp C, Rhaiem T, Schleppers A, St. Pierre M. Partikelkontamination nach dem Aufziehen von Arzneimitteln - Ein relevantes aber lösbares Problem. ZEFQ 2013; 107:352-355

21. Levy B, Fritz C, Tahon E, Jacquot A, Auchet T, Kimmoun A. Vasoplegia treatments: the past, the present, and the future. Crit Care. 2018;22:52

22. Hazarika A, Singh GP, Malik V, Bithal PK. Vasoplegic syndrome: a challenge to anaesthetic management. J Neuroanaesthesiol Crit Care. 2018:2(2):139-41.

23. Barbosa Evora PR, Alves L, Ferreira CA, Menardi AC, Bassetto S, Rodrigues AJ, Scorzoni A, de Andrade Vicente WW. Twenty years of vasoplegic syndrome treatment in heart surgery. Methylene blue revised. Rev Bras Cir Cardiovasc. 2015;30(1):84-92.

24. Shanmugam G. Vasoplegic syndrome - the role of methylene blue. Eur J Cardiothorac Surg. 2005:28(5):705-10.

25. Matthay MA, Zemans RL. The acute respiratory distress syndrome: pathogenesis and treatment. Michael A Annu Rev Pathol. 2011;6:14763.

26. Lopes JA. The RIFLE and AKIN classifications for acute kidney injury: a critical and comprehensive review. Clin Kidney J. 2013;6(1):8-14.

27. Giannoudis PV, Harwood PJ, Loughenbury P, Van Griensven M, Krettek C, Pape HC. Correlation between IL-6 levels and the systemic inflammatory response score: can an IL-6 cutoff predict a SIRS state? J Trauma. 2008;65(3): $646-52$.

28. Brun-Buisson C. The epidemiology of the systemic inflammatory response. Intensive Care Med. 2000;26(1):64-74

29. Ma L, Zhang H, Yin YL, Guo WZ, Ma YQ, Wang YB, Shu C, Dong LQ. Role of interleukin-6 to differentiate sepsis from non-infectious systemic inflammatory response syndrome. Cytokine. 2016;88:126-35.

30. ORBIS AGFA HealthCare, Bonn, Germany.

31. Metavision iMDsoft, Tel Aviv, Israel.

32. R Foundation for Statistical Computing, Vienna, Austria.
33. BiAS for Windows, epsilon-Verlag, Frankfurt/Main, Germany (maintained by Institute of Biostatistics, Goethe University Frankfurt, Germany).

34. G*Power, Heinrich Heine University of Duesseldorf, Germany.

35. Gradwohl-Matis I, Brunauer A, Dankl D, Wirthel E, Meburger I, Bayer A, Mandl M, Dünser MW, Grander W. Influence of in-line microfilters on systemic inflammation in adult critically ill patients: a prospective, randomized, controlled open-label trial. Ann Intensive Care. 2015;5:36.

\section{Publisher's Note}

Springer Nature remains neutral with regard to jurisdictional claims in published maps and institutional affiliations.
Ready to submit your research? Choose BMC and benefit from:

- fast, convenient online submission

- thorough peer review by experienced researchers in your field

- rapid publication on acceptance

- support for research data, including large and complex data types

- gold Open Access which fosters wider collaboration and increased citations

- maximum visibility for your research: over $100 \mathrm{M}$ website views per year

At BMC, research is always in progress.

Learn more biomedcentral.com/submissions 